\title{
An experimental investigation on Inconel 718 interrupted cutting with ceramic solid end mills
}

\author{
Paolo Parenti ${ }^{1}$ - Francesco Puglielli ${ }^{2} \cdot$ Massimo Goletti $^{2} \cdot$ Massimiliano Annoni $^{1} \cdot$ Michele Monno $^{2}$
}

Received: 1 January 2021 / Accepted: 20 April 2021 / Published online: 29 May 2021

(C) The Author(s) 2021

\begin{abstract}
Solid ceramic end mills for machining heat resistant super alloys (HRSA) have the potential to generate higher material removal rates, up to one order of magnitude, with respect to standard carbide tools. The machining operations in aerospace industry, where large removals are required to obtain tiny and slender parts like turbine blades, is a cost-intensive task that can benefit of the adoption of ceramic solid end mills. However, these tools show a quite limited tool life, especially when used with interrupted tool engagement strategies. Moreover, they might induce heat-related problems in the workpiece material surface integrity. This paper investigates the cutting and the tool wear during milling Inconel 718 with solid $ø 12 \mathrm{~mm}$ cutting end tool made by SiAlON. The wear mechanisms are studied together with their effects on process signals as cutting forces and power, measured via external and $\mathrm{CNC}$ integrated sensors. The carried experimental campaign allowed to find out that tool clogging and edge chipping were the primary cutting phenomena leading the tool wear. Cutting strategy (downmilling or upmilling) produced different results in terms of tool wear sensitivity and process outputs whereas upmilling configuration showed the best results in terms of cutting signals stability and surface integrity. At the same time, cutting speed was found to increase the cutting power more in upmilling than downmilling cutting. The analysis of the forces and power demonstrated that the typical tool wear mechanisms can be traced by signal monitoring due to their high impact on cutting processes. This fact shows the good potential of signal monitoring for a better tool life evaluation.
\end{abstract}

Keywords Inconel $\cdot$ Milling $\cdot$ Ceramic $\cdot$ SiAlON $\cdot$ Cutting forces $\cdot$ Cutting power $\cdot$ Wear

\section{Introduction}

The developments of ceramic end mills are recently deserving lot of attention from the energy and aerospace industries because they are demonstrating to be a viable and effective tooling solution for efficient cutting of HRSA, widely adopted in these application fields [1]. The strongest properties that make the HRSA alloys, as the Inconel 718, so interesting are their excellent temperature strength and low thermal conductivity, but these properties, together with the severe work hardening tendency, are strong obstacles for the material

Paolo Parenti

paolo.parenti@polimi.it

1 Department of Mechanical Engineering, Politecnico di Milano, via La Masa 1, 20156 Milano, Italy

2 MUSP Laboratory, Str. della Torre della Razza, 29122 Piacenza, Italy machinability $[1,2]$. Therefore, HRSA materials ask for large cutting forces, and in addition, chips are easy to weld on the tool to form build up edge (BUE) [3, 4]. As a result, cutting tool wears rapidly during machining. Ceramic tools tackle these limits by allowing to cut at extremely higher temperatures with respect to coated carbides, even close to melting temperature of the workpiece materials [4]. In fact, thanks to their enhanced thermal stability and hot hardness, these tools used in dry cutting induce a strong thermal softening on the workpieces (starting from 700 to $800{ }^{\circ} \mathrm{C}$ for the Inconel 718) that allows to reduce forces and then increase productivity rates up to one order of magnitude bigger than carbide end mills $[5,6]$. This is because very high cutting speed ranges (up to $700-800 \mathrm{~m} / \mathrm{min}$ ) can be adopted (even though with reduced radial depth of cuts). The market revolution of ceramic milling tools started 4-5 years ago when some tool manufacturer showed the innovative capacity to produce complex ceramic end mills with monolithic design, suitable for roughing operations on 3D parts, like turbine blades [7]. Ceramic mills are however less resistant to transverse and impulse stresses 
making these tools more sensible to cutting parameter variations and more susceptible to develop catastrophic tool wear mechanisms like tool breakage [7]. Other challenges are related to their tendency to generate detrimental effects on the workpiece's surface integrity due to the high thermalmechanical stresses induced by the high-speed milling that can reflect on the results of the subsequent finishing operations or even affect the final component properties [4]. The cost effectiveness of these innovative tools can only be evaluated if proper knowledge is developed about their machining and wear behaviors and their impact on the machine and workpiece environments [8].

This work studies the behavior of SiAlON end mills with diameter $\varnothing 12 \mathrm{~mm}$ in rough machining of Inconel 718. This experimental-based investigation reports about the tool wear mechanisms involved and their impact on surface generation and provides a way to monitor the cutting process and tool wear state by means of cutting forces and numerical control (NC) signals. The experimental conditions are described and then microstructures analysis of both workpiece and tools are presented. Tool failure modes and the analysis of cutting mechanisms are then followed by the cutting monitoring analysis. Discussion and conclusion close the manuscript.

\section{Materials and method}

\subsection{Workpiece materials}

The selected material Inconel 718 alloy was aged and cut in rectangular blocks with dimensions of $60 \times 100 \times 50$ $\mathrm{mm}$. Finishing by grinding was applied to generate flat and homogenous surfaces for the milling operation ( $\mathrm{Ra}$ $<0.4 \mu \mathrm{m})$. Initial hardness of the material was in the range of 52-54 $\mathrm{HRC}$.

\subsection{Cutting tools}

Prototypes ceramic SiAlON monolithic milling tools were specifically produced and adopted for the experimental campaign. The tool material belongs to the class of SiAlONs, which are ceramic alloys based on Silicon Nitride and Aluminum Oxide. This innovative material has been designed to overcome the limits of the standard Silicon Nitride $\mathrm{Si}_{3} \mathrm{~N}_{4}$ ceramics, such as the inadequate fracture toughness, hardness, and its high reactivity with the workpiece [9, 10]. The tools were characterized by a diameter of $12 \mathrm{~mm}, 6$ cutters, flute helix angle of $35^{\circ}$, radial rake angle of $-5^{\circ}$, axial rake angle of $2^{\circ}$, and cutting-edge radius of about $10 \mu \mathrm{m}$, obtained by honing process.

\subsection{Machine and measurements}

An accurate 5-axis machining center (Mikron HPM 450U) equipped with a 20,000 rpm spindle (HSK 63) and a Heidenhain iTNC530 Numerical Controller were adopted for the testing, Fig. 1. A Kistler dynamometer 9257BA was mounted on a fixturing plate (System 3R) that was installed on the machine table. The workpieces were fixed on the Kistler table through bolt connection. The dynamometer allowed to measure (after dynamic compensation) the cutting forces (at $10 \mathrm{KHz}$ of acquisition frequency) applied to the workpiece in the three machine axes directions X, Y, and Z, Fig. 1. The absorbed cutting power was acquired during the tests by exploiting the TNCscopeNT software that allows to read the drive signals from the NC units. These signals were acquired at $333 \mathrm{~Hz}$. One thermocouple fixed in the middle of the side face at $5 \mathrm{~mm}$ from the upper surface was used to measure the workpiece average increase of temperature. The surface roughness computation of the parts was obtained via a portable roughness tester (Tesa Rugosurf 20) by measuring the surface in the middle of each cutting slots.

\subsection{Experimental plan and cutting conditions}

The experimental trials consist of a series of interrupted face milling and contouring operations. In face milling operation, the radial engagement was set to $7.25 \mathrm{~mm}$ (around $60 \%$ of the diameter, Table 1). All the cutting passes were conducted in both upmilling dominant and downmilling dominant regimes (Table 1). Eight (8) passes were conducted to fully machine a single plane of the workpiece by using an interrupted

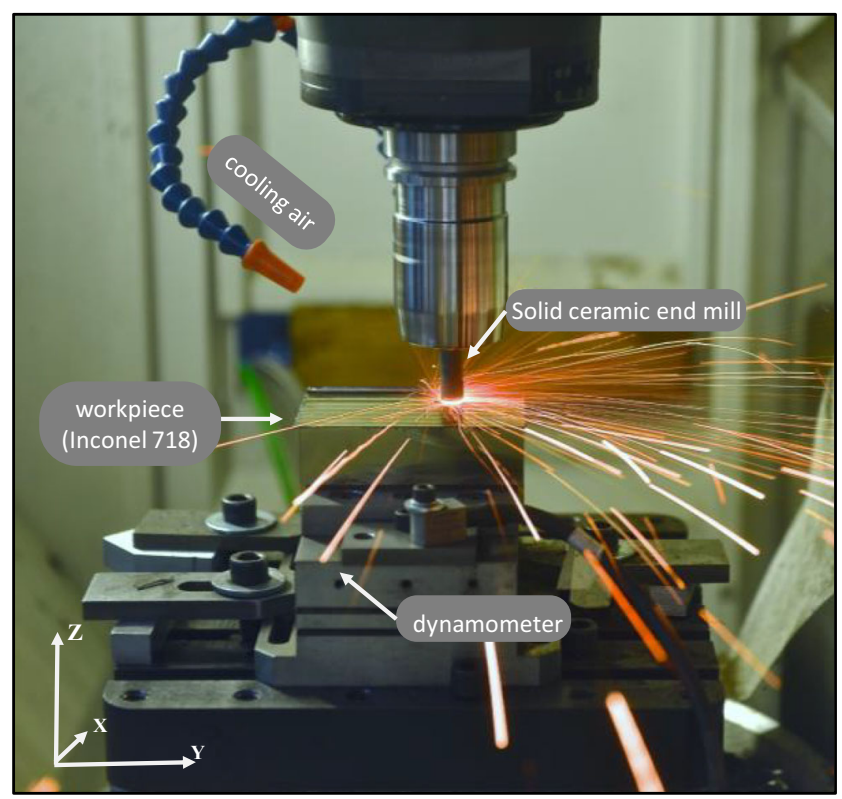

Fig. 1 Cutting setup during face milling with ceramic tools 
Table 1 Tested cutting parameters

\begin{tabular}{lll}
\hline & Value 1 & Value 2 \\
\hline Cutting speed Vc [m/min] & 550 & 650 \\
Spindle speed [rpm] & 14,589 & 17,242 \\
Feed per revolution fz [mm/tooth] & 0.02 & \\
Feed speed Vf [mm/min] & 1751 & 2069 \\
Radial depth of cut ae[mm] & 7.25 & \\
Axial depth of cut ap [mm] & 0.5 & \\
Cutting type & Upmilling & Downmilling \\
\hline
\end{tabular}

direction-parallel strategy aligned with Y machine direction and workpiece length. With this strategy, a cutting interruption is generated every $100 \mathrm{~mm}$ of cutting length, i.e., the workpiece length. In total, 16 planes for a total of 128 passes were conducted (total cutting length of around $12.8 \mathrm{~m}$ ) with each tool generating a contact time of about 6.2-7.3 $\mathrm{min}$ (one for each of the two set of tools used) and an overall removed volume of $46.4 \mathrm{~cm}^{3}$.

Workpieces and tools were inspected after 64 passes of tool-workpiece contact (8 planes). Dry cutting was prescribed in order to avoid external thermal shock to the tools [11].

Air blow was used to help chip evacuation from the cutting zone. Two cutting speeds were tested considering the constraints given by the spindle - a security value of $18,000 \mathrm{rpm}$ (out of the 20,000 rpm available) was chosen as maximum usable value - and typical application speeds of ceramic tools around $600 \mathrm{~m} / \mathrm{min}$. For each value of cutting speed, both upmilling and downmilling machining were performed. A linear interpolation (ramp) of the feed was used at tool entry for reducing entry chip load moving from $30 \%$ of the nominal feed to a $100 \%$ in half the tool diameter. The 4 cutting conditions were replicated 3 times for a total of 12 tests performed on 12 different tools.

\section{Results}

In all the conducted tests, tools experienced moderate, severe, and catastrophic tool wear indicating that the selected cutting conditions and strategies were tough for the tools. The interrupted cutting seemed to play a big role in the determination of the severe cutting conditions especially regarding the reuse, after the interruption and the off-line inspection, of clogged tools.

During all the tests, the generated chips were in the form of small particles and pulverized hot chips. This sparks flux (despite the constant directing effect of the air blow) and the sound emitted from the cutting were not constants within the passes and between the cutting replicas indicating that the process replicability was somehow limited.
The machined surfaces showed a general poor finishing quality with a relevant presence of smeared and adhered chip and relevant traces of oxidation due to the generous amount of heat produced by the cutting.

\subsection{Cutting process mechanisms}

During high-speed milling operations with ceramic tools, the most important phenomenon is the workpiece thermal softening $[11,12]$. However, due to the latter, the generated chip may be not easily evacuated. BUE was observed. Chip adhesion phenomena were accentuated. Flute clogging happened extensively. Moreover, the working temperature is locally so high that the chemical interaction between tool, chip, and workpiece could have been occurred. This situation can also lead to preliminary tool cratering (as verified in $[4,5]$ ). In this scenario, the cutting geometry can be easily compromised. Ploughing occurs instead of shearing and the friction increases, provoking a further temperature ascent.

As a main effect of the cutting geometry modification, mostly due to clogging, an increasing power absorption can be generated which can end with the tool damaging or sudden declogging. If the failure is not destructive and the operations are not stopped, a sort of re-sharpening of the cutting edge can occur, leading to a sudden decrease of the absorbed spindle power. The same effect can be noticed if declogging happens. This route was normally repeated while milling until the tool was compromised or the operation finishes.

\subsection{Visual inspection of the tools}

All the tests (both downmilling and upmilling) showed a relevant amount of clogging, making impossible to inspect the tools accurately at the intermediate checking. In fact, tools were not cleaned trying not to damage them or alter their conditions. Most of the times, the tools were found to be clogged in the flute channels and in the bottom area by highly oxidized and smeared chip, Fig. 2a. Part of this material seemed to be simply attached to the tools, other seemed to be welded. Chipping occurred extensively on the tools during all the different cutting. In some cases, notch wear on the peripheral cutting edge at a length much higher at the used axial depth of cut were noticed. This was found to be related with the $2 \mathrm{~mm}$ thick cutting lip, not cut by the tool during the facing of each plane on the workpiece (the workpiece was $60 \mathrm{~mm}$ wide while the 8 tool passes for each plane extended for only $58 \mathrm{~mm}$ ). Occurrences of single/multiple tooth/teeth breakage were found, sometimes preventing the execution of the second part of the cutting passes after the tool inspection. The observed failure modes are depicted in Fig. 2 and summarized in Table 2. For what concerns downmilling tests, they seemed to generate more damaging events, with high variability between the three tool replicas tested. For the lower cutting 

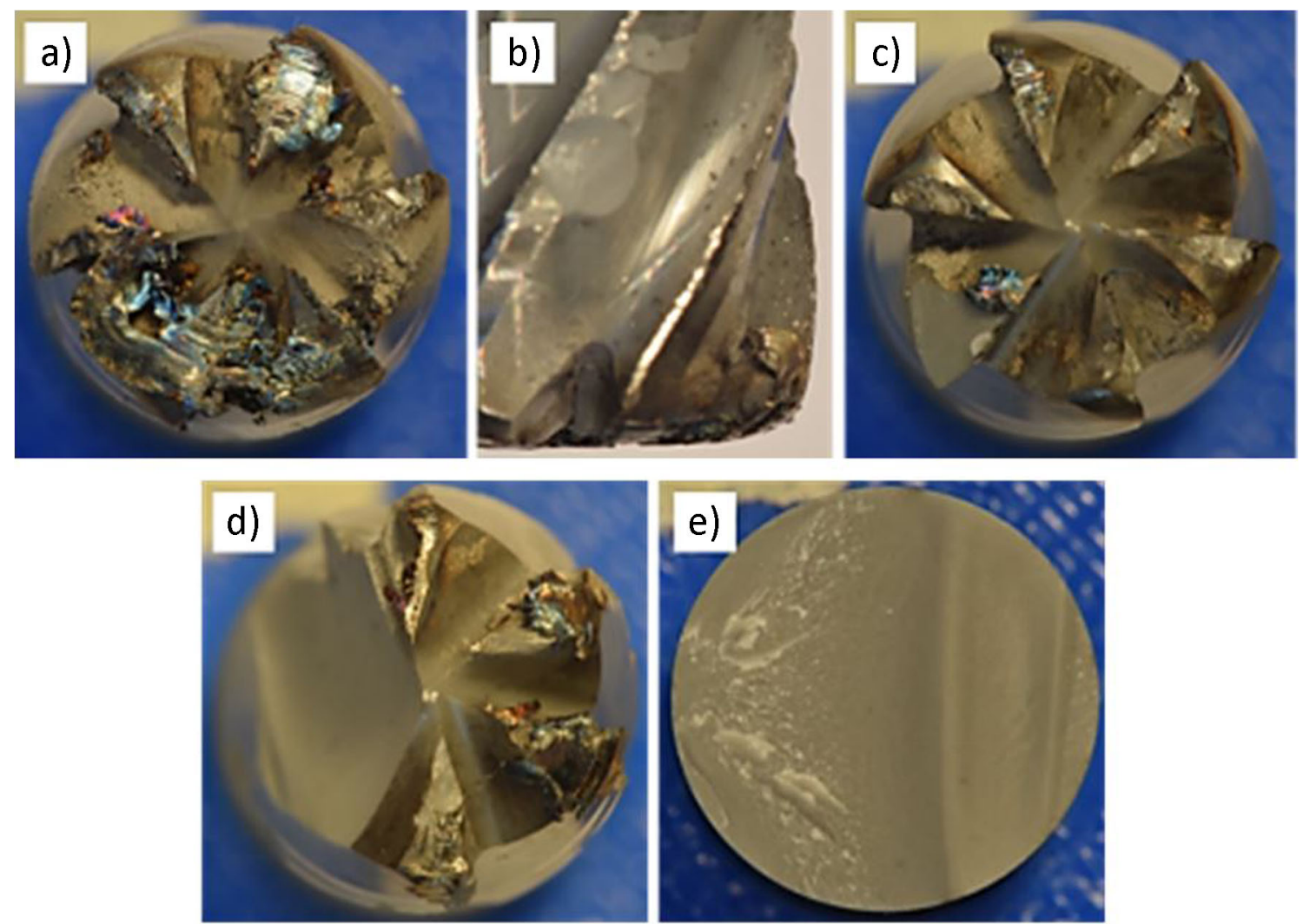

Fig. 2 Tool failure modes experienced: a flute clogging, b chipping/notch wear, $\mathbf{c}$ single tooth loss, $\mathbf{d}$ multiple teeth loss, e shank fracture

speed adopted two-thirds of the tools did not reach the end of the prescribed cutting length. For the higher speed, two-thirds of the tools showing severe wear. The upmilling tests showed a good reliability and repeatability for both the speed velocities. All the tools reached half of the cutting length imposed showing chipping and relatively limited wear.

\subsection{Visual inspection of the machined surfaces}

Table 2 summarized the perceived response of the machined surfaces. The first evidence on each Inconel samples was the presence of surface burn and side material flow on the machined surfaces; the presence of oxidized metal (yellowishbrown color) and non-uniform finishing were easily detectable. In particular, the low cutting speed tests $(\mathrm{Vc}=550$ $\mathrm{mm} / \mathrm{min}$ ) were characterized by high oxidation in both downmilling and upmilling cases as demonstrated in past works [13]. The oxidation was reduced with the increased speed, but it often resulted in a ununiformed pattern. In general, a lower oxidation was found in the second part of each test (after about 3 min of cutting time), when the tool presented a higher degree of wear and clogging. For what concern the amount of superficial oxidation, the best case was represented by upmilling machining. For what concern the surface appearance, the low Vc tests were characterized by a bad surface finishing and high inhomogeneity, especially in downmilling case, Fig. 3. Vibrational phenomena were felt during upmilling case with worn tool, i.e., in the second part of the tests after tool inspection. In the downmilling with higher Vc, the surface integrity was severely compromised, with very poor roughness and massive surface burrs. The best appearance was found when machining with lower Vc in upmilling, although it increased with the tool wear usage. This kind of inspection could help in recognizing when re-sharpening occurred. The surface roughness was compromised while clogging occurred and suddenly refined if the self-declogging happened (Fig. 4).

\subsection{Surface roughness}

The plotted values of Ra and Rt in Fig. 5 highlight the presence of a fluctuating trend in the generated surface part finishing due to the current status of the tools. Clogged flutes and sharpened edges due to teeth damages and chipping caused evident fluctuation of surface roughness, oxidation, and damages (which strongly alter the $\mathrm{Rz}$ values up to 50 $\mu \mathrm{m})$ which could alter the achievable surface in nickedbased superalloys machining [14]. These fluctuations seem to have a periodicity repeating every $3-4$ cutting passes, which are also observed in the average force and power signature fluctuations. The second and third showed graph of Fig. 5 depicts two test replicas, i.e., where two different tool 
Table 2 Workpiece surfaces and tools inspection summary (test number refers to the same tool inspected at two different cutting length)

\begin{tabular}{|c|c|c|c|c|c|c|c|c|}
\hline \multirow[b]{2}{*}{ Test \# } & \multirow[b]{2}{*}{ Cutting length $[\mathrm{m}]$} & \multirow[b]{2}{*}{ Strategy } & \multirow[b]{2}{*}{$\mathrm{Vc}[\mathrm{m} / \mathrm{min}]$} & \multicolumn{2}{|l|}{ Workpiece } & \multicolumn{3}{|l|}{ Tool } \\
\hline & & & & Surface burn & Surface clogging & Flute clogging & Edge chipping & Teeth shark fracture \\
\hline 3 & 6.4 & Downmilling & 550 & $\bullet \bullet$ & & $\bullet$ & & \\
\hline 6 & & & & $\bullet \bullet$ & $\bullet$ & & & $\bullet \bullet$ \\
\hline 9 & & & & & $\bullet$ & & $\bullet \bullet$ & $\bullet \bullet$ \\
\hline 2 & & & 650 & $\bullet$ & & & & \\
\hline 5 & & & & $\bullet$ & $\bullet$ & $\bullet$ & & $\bullet \bullet$ \\
\hline 12 & & & & & & $\bullet \bullet$ & $\bullet \bullet$ & $\bullet$ \\
\hline 4 & & Upmilling & 550 & $\bullet \bullet$ & $\bullet$ & & & \\
\hline 7 & & & & $\bullet$ & $\bullet$ & $\bullet$ & & \\
\hline 10 & & & & $\bullet \bullet$ & & & & \\
\hline 1 & & & 650 & $\bullet \bullet$ & & $\bullet$ & $\bullet$ & \\
\hline 8 & & & & $\bullet$ & $\bullet$ & & & \\
\hline 11 & & & & $\bullet \bullet$ & & & & \\
\hline 3 & 12.8 & Downmilling & 550 & $\bullet$ & $\bullet \bullet$ & & & $\bullet \bullet$ \\
\hline 6 & & & & $N A$ & $N A$ & $N A$ & $N A$ & $N A$ \\
\hline 9 & & & & $N A$ & $N A$ & $N A$ & $N A$ & $N A$ \\
\hline 2 & & & 650 & $\bullet$ & & & $\bullet$ & \\
\hline 5 & & & & $N A$ & $N A$ & $N A$ & $N A$ & $N A$ \\
\hline 12 & & & & & $\bullet \bullet$ & & $\bullet \bullet$ & $\bullet \bullet$ \\
\hline 4 & & Upmilling & 550 & $\bullet \bullet$ & & $\bullet$ & & \\
\hline 7 & & & & & $\bullet \bullet$ & $\bullet \bullet$ & $\bullet$ & \\
\hline 10 & & & & & $\bullet$ & $\bullet \bullet$ & $\bullet$ & \\
\hline 1 & & & 650 & & $\bullet$ & $\bullet \bullet$ & $\bullet \bullet$ & \\
\hline 8 & & & & $\bullet \bullet$ & $\bullet$ & $\bullet \bullet$ & $\bullet$ & \\
\hline 11 & & & & $N A$ & $N A$ & $\bullet \bullet$ & $\bullet$ & \\
\hline
\end{tabular}

Absent

- Moderate

-• Severe

units were used with the same cutting conditions. This seems to confirm that process replicability in surface generation was not only strongly varying within the same cutting but also between the different tools.

\subsection{Signal monitoring}

\subsubsection{Workpiece temperature}

The process thermal signature seriously affected the parts during the tests. The type of sensor used did not allow to trace the instantaneous temperature of the work-tool contact point but was still able to produce an evaluation of the average part temperature increase.

The average thermal response of the part, as read by the sensor, is depicted in Fig. 6. The average increase of temperature per milled plane is low $\left(\sim 20^{\circ} \mathrm{C}\right)$ but local rapid increases were recorded (for few seconds) up to $280{ }^{\circ} \mathrm{C}$ on the part at a $1 \mathrm{~mm}$ distance from the cutting point (at the eighth cutting plane, the thermocouple did reduce its distance from the cutting zone since the tool removed $4 \mathrm{~mm}$ of workpiece material). In any case, an increase of the bulk part temperature (up to 140 ${ }^{\circ} \mathrm{C}$ ) was observed. Despite this increase seems negligible in absolute, it could have triggered a thermal softening on the workpiece that could have affected the cutting forces and power signatures.

\subsection{Spindle power}

In the behavior of the power signal, a proof of the process plan can be recognized. Since the face milling was performed by eight milling passes on each plane of the workpiece and in total 16 planes were machined, then 16 groups of 8 peak regions were found in the power profile of each tested tool.

Despite the limited acquisition frequency, these signals showed strong noise, coming from process fluctuations. In order to get a synthetic indicator of the spindle power 


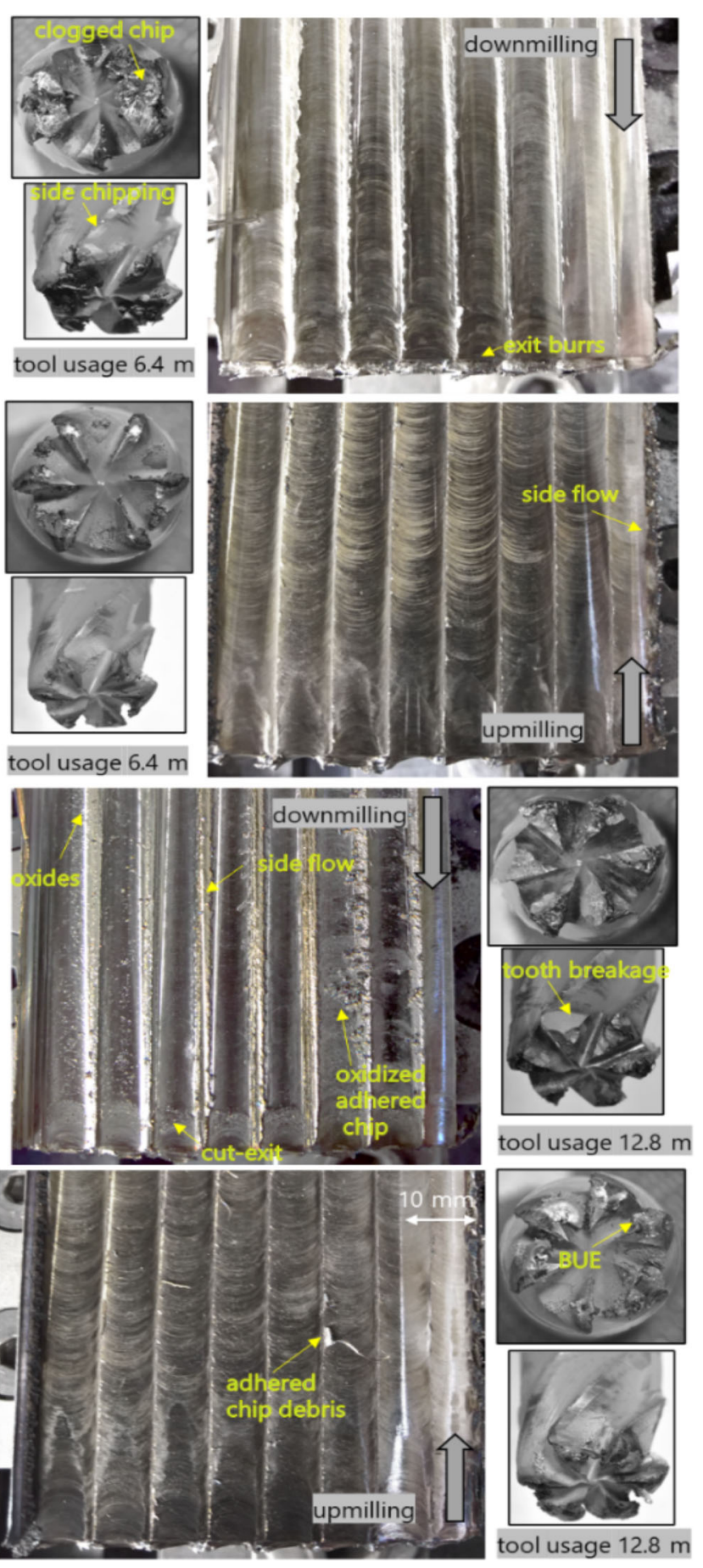

Fig. 3 Surface generation $(\mathrm{Vc}=650 \mathrm{~m} / \mathrm{min})$ with different tool usage: $3.1 \mathrm{~min}-64$ passes (above) and $6.2 \mathrm{~min}-128$ passes (below)

acquired in each milling pass, the mean value of the signal corresponding to each milling pass was considered. It was decided not to consider the boundary milling passes, i.e., the first and the last one of each plane, because they were slightly affected by the different tool-part engagement conditions. In particular, the first pass was different from the others because the $40 \%$ of the tool bottom area

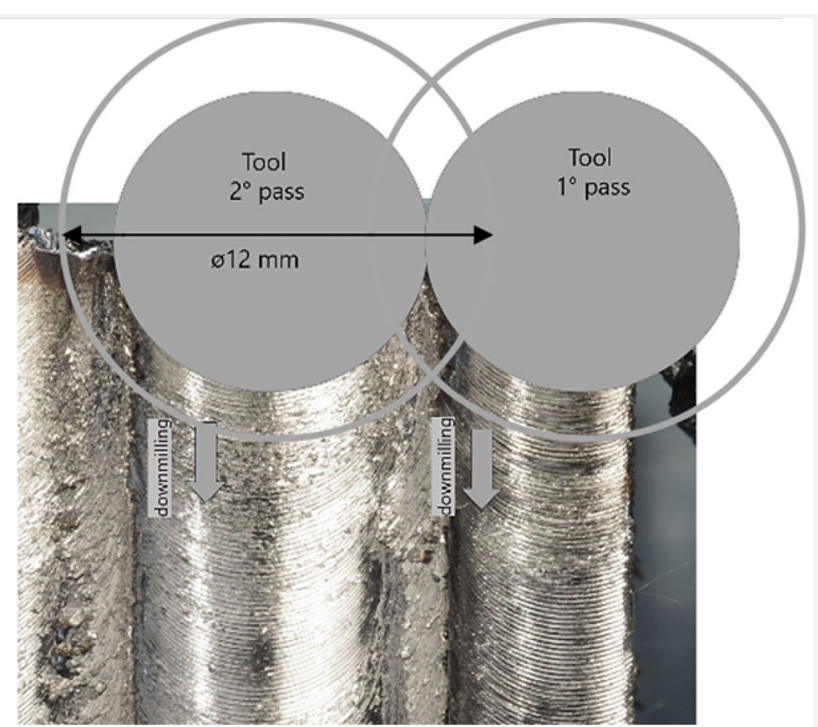

Fig. 4 Surface generation. Zoom of 120 and 121 passes of downmilling test

was in air, i.e., not touching the part surface (because radial tool engagement was ae $/ \mathrm{D}=60 \%$ and the first pass started from lateral workpiece margin). This fact brought in average to a reduction of the absorbed power of around $25-35 \%$ (Fig. 7) indicating that cutting phenomena components like friction, ploughing, and re-machining on the bottom tool edges can play a strong role; finally, this condition certainly fosters the tool declogging and the chip evacuation simplifying the tool cutting action. Basing on these considerations, the difference between the first and the subsequent cutting passes powers was noticed to be related with the tool state, whereas tools in bad conditions tended to generate bigger power bias.

The average absorbed power in the tests was around $2.3 \mathrm{~kW}$ but variations were observed with the cutting conditions and the tool wear state. As expected, cutting speed played a significant role not only in the determination of the power but also the cutting configuration did (Fig. 8) where upmilling led to a statistically significant increase of around $10 \%$. As can be observed, upmilling tests seemed to give more power homogeneity between replicas, while the downmilling tests gave more dispersion: in particular, tests 5 and 9 gave in a significant less average power than their replicas. This can be directly linked to the cutting behavior of downmilling tools that were characterized by more dominant chipping and edge sharpening. This mechanism was more severe for these two tools making them apparently capable to cut better with reduced power; indeed, this effect finally led these tools to develop a catastrophic wear, with completely teeth breakage.

All the tools showed a wear-in period typically bigger than 5-7 passes after which the absorbed power reaches more than $70 / 80 \%$ of its maximum values, Fig. 9. After this phase, power fluctuations between and within the cutting passes were very 
Fig. 5 Roughness values acquired during three tests
$\mathrm{Vc}=550[\mathrm{~m} / \mathrm{min}] ;$ downmilling

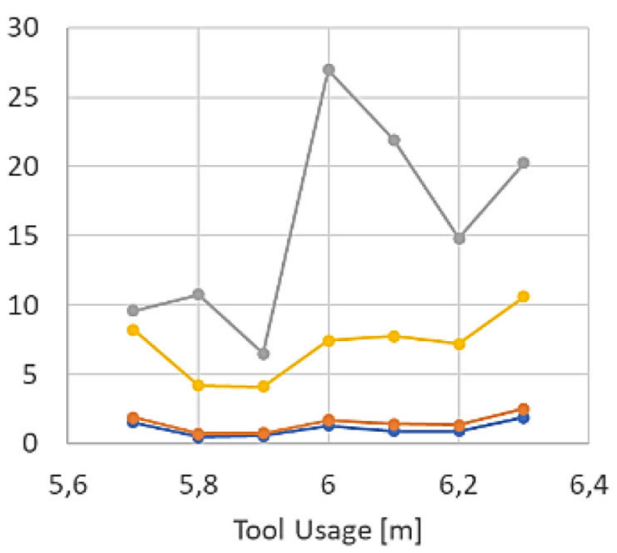

$V_{c}=650[\mathrm{~m} / \mathrm{min}] ;$ downmilling

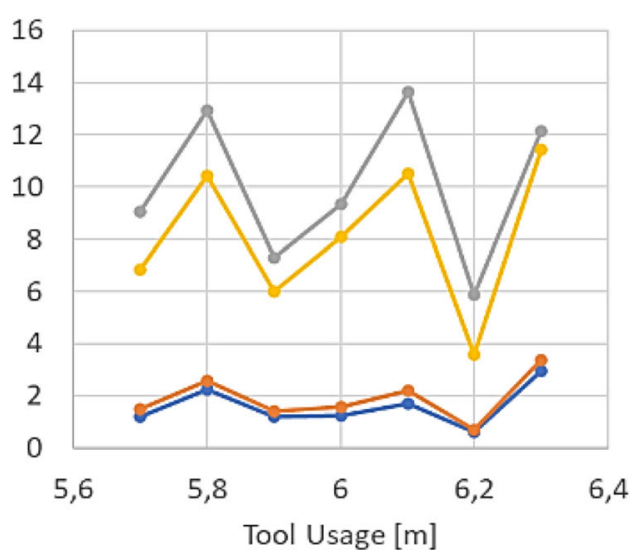

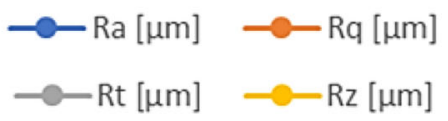

$V_{c}=650[\mathrm{~m} / \mathrm{min}] ;$ downmilling

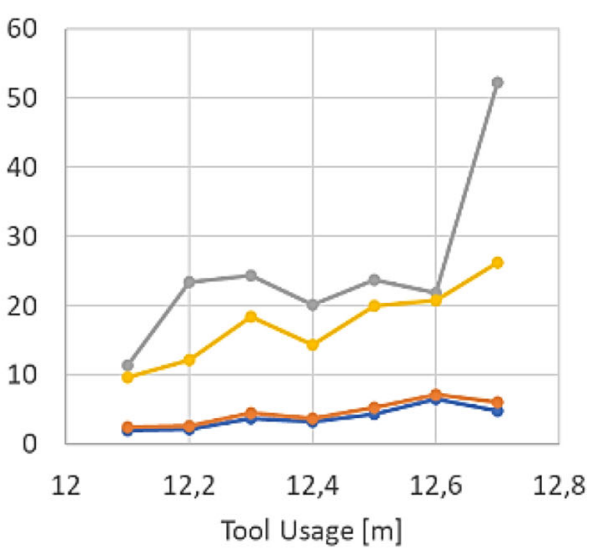

different for the various tested tools. Despite the wear development, upmilling tests stabilized the power after the wear-in around an average value while downmilling cutting generated big variations around an increased power level without any specific tool-wear trend.

\subsubsection{Anomalous cutting conditions identification}

The spindle power signal acquired through the TNCScope software demonstrated to be a useful tool to understand some anomalies and unpredicted events that take place during the
Fig. 6 Workpiece temperature measurement with thermocouples during test $1(650 \mathrm{~m} / \mathrm{min}$, upmilling)

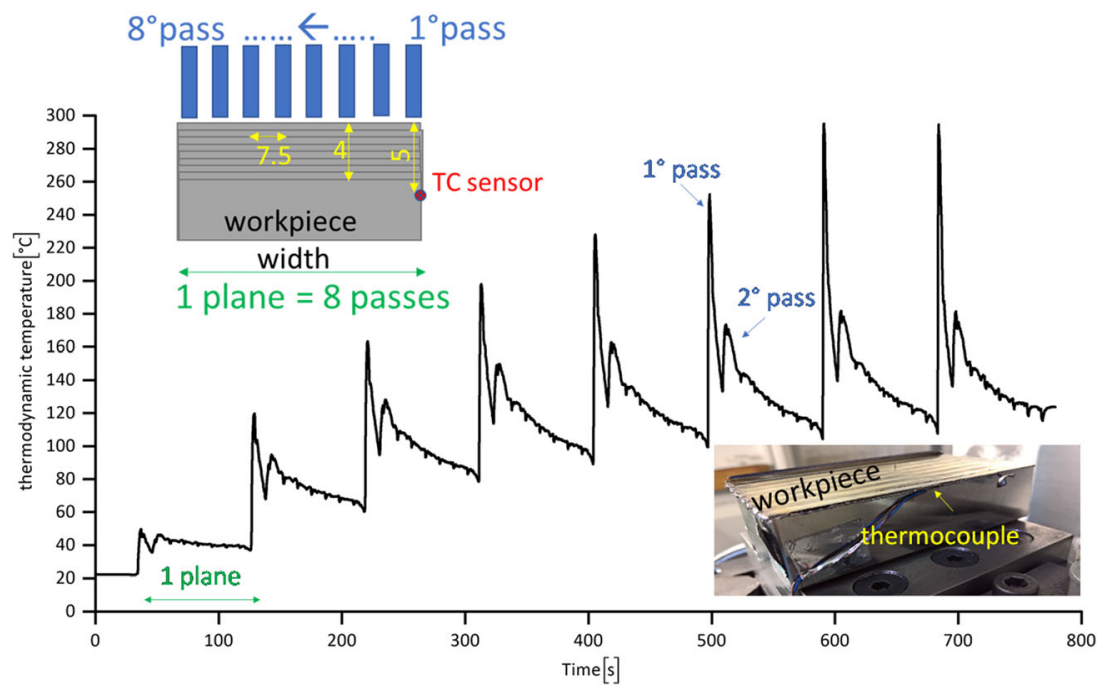




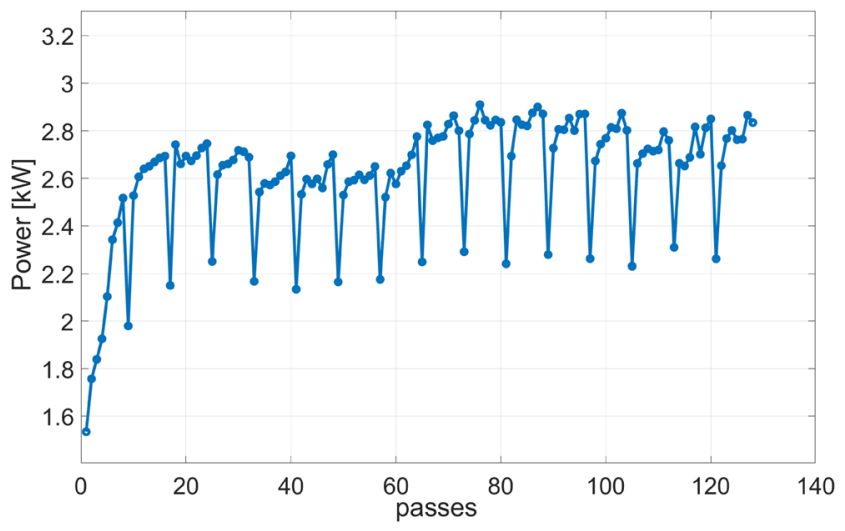

Fig. 7 Spindle power signal (average value at each pass) acquired during test $11(\mathrm{Vc}=650 \mathrm{~m} / \mathrm{min}$, upmilling $)$

milling process. By observing the power trend in Fig. 10 that corresponds to a downmilling test, it can be noticed that there are two anomalous regions in which the spindle electrical power required decreases suddenly and rapidly increases.

These parts can be likely associated with the tool chipping occurrence which exposed new - i.e., sharpened - fractured edges to the cutting, in non-durable manner as confirmed by the tool inspection after the cutting. At the same time, despite these, the declogging and chipping phenomena are in aliasing, the other minor fluctuations which can be seen can be associated with the self-declogging of the tool, being this latter probably less impacting on the cutting geometry.

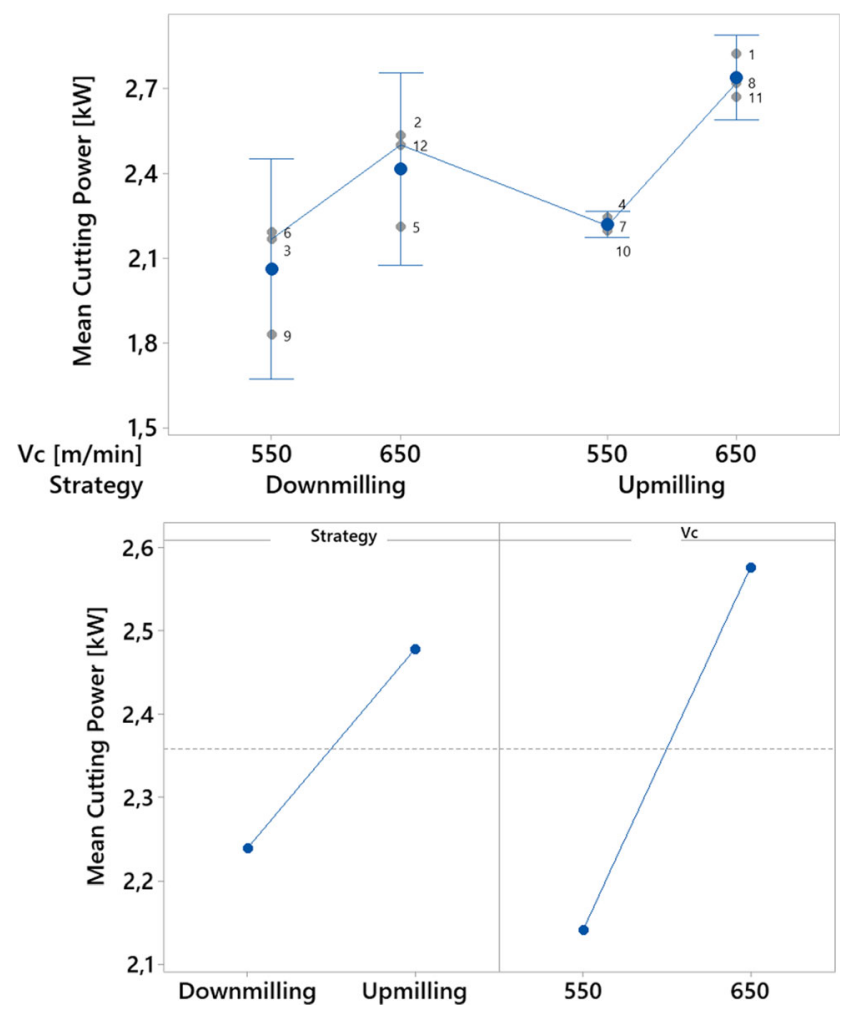

Fig. 8 Acquired (average-per-cutting pass) spindle power: individual value plot (above), main effect (below)

\subsection{Cutting forces}

The forces were first evaluated as average root mean square (RMS) values along all the passes of a tool, Fig. 11. The force in vertical $(Z)$ direction was always bigger than the cutting plane (XY) components. This was probably due to the clogging effect which prevented the end cutting edges to work properly. As can be seen, there are some tests that exhibit force values clearly different from the others, e.g., test 7 in Fig. 11, but there is no experimental evidence to discard these measurements.

The mean values of the RMS of the cutting forces clearly increase when the strategy is changed from downmilling to upmilling and when the cutting speed increases from 550 to $650 \mathrm{~m} / \mathrm{min}$. This last result obviously indicates that the cutting coefficients are related with cutting speed.

The time domain plot of the forces, Fig. 12, confirms the fact that the development of the tool entry was different for the upmilling and downmilling cases, whereas the former gave more irregular tool entry with higher force peaks, especially in $\mathrm{Z}$ direction.

Instantaneous values of the cutting forces, Fig. 12, indicate that the process was stable and an important phenomenon at spindle frequency (SF) was present. A different state of the various flutes (see above) clearly leads to a SF component [15] (Fig. 13).

\section{Discussion and conclusion}

This experimental study was aimed at investigating the behavior of prototype monolithic SiALONs end mills when cutting aged Inconel 718. On paper, these innovative end mill materials guarantee extremely large improvements in productivity and cutting performances with respect to coated carbides. On one side, the potential is so strong that can wipe the carbides out from the Inconel machining fields but there are still aspects that wait for being completely understood and that can prevent this eventuality. There are situations, as the tested interrupted cutting, which can additionally hinder the ceramic end mill performances in terms of cutting mechanisms and wear development. This scenario however commonly occurs in real situations, especially where small components with complex features need to be machined with end mills by using "standard" CNC centers.

The use of extreme process parameters, as the tested ones in this work, led to catastrophic tool wear events despite the limited tool usage and the adopted tight control of the cutting boundary conditions. The experimental tests produced widely varying outcomes that confirm the leading role of the brittle fracture dynamic of these ceramic 
Fig. 9 Spindle power signals in downmilling and upmilling tests $(\mathrm{Vc}=550 \mathrm{~m} / \mathrm{min})$
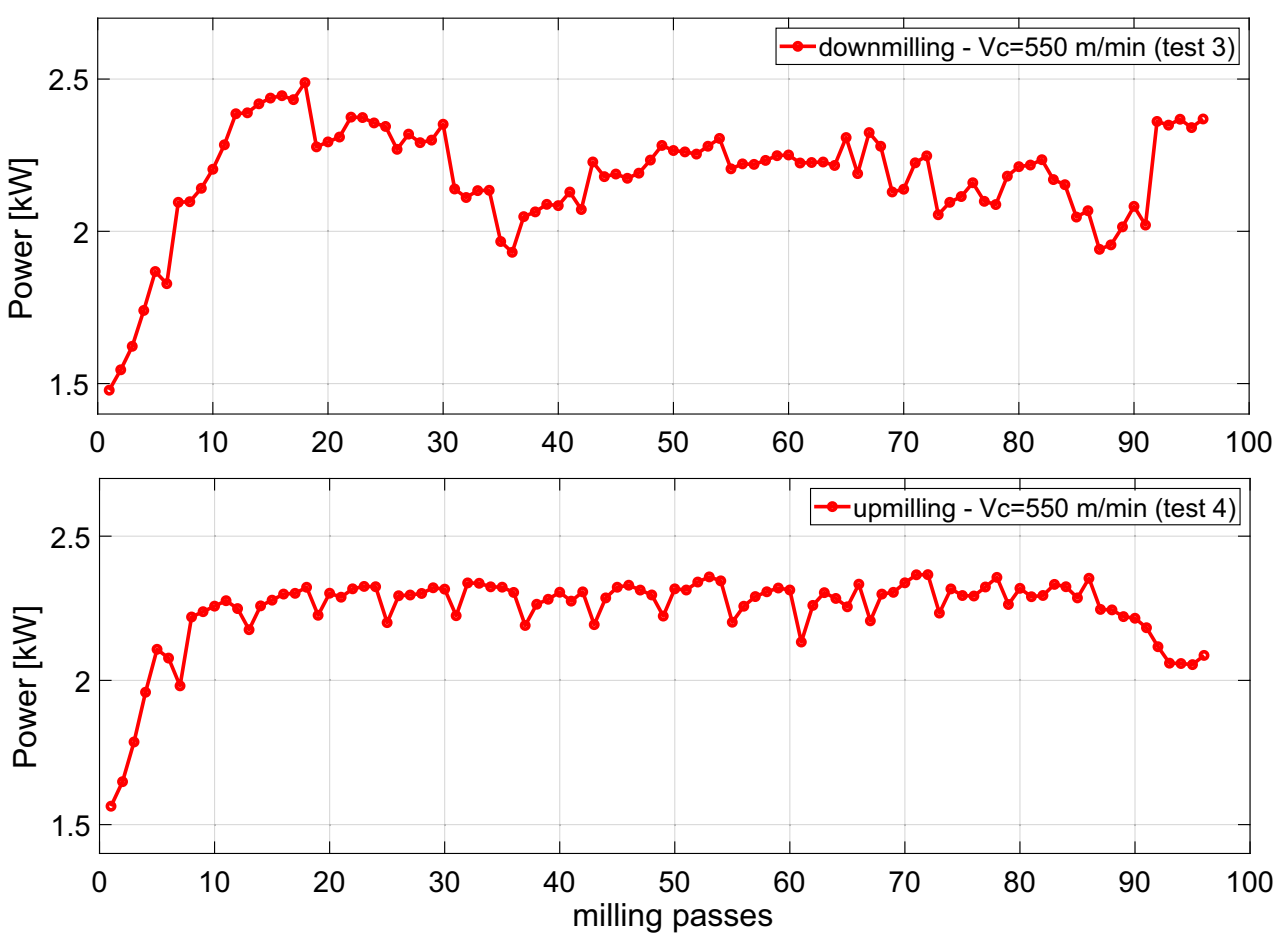

tools together with the yet not well understood processes that lead to their wear.

Quite big differences were pointed out from the conducted test between the downmilling and upmilling cutting configurations in terms of tool wear, power absorptions, and surface generation, whereas the latter type guaranteed better results.

The study provided some additional insight into the exploitation of cutting related signals, as the power and forces for improved process comprehension and optimization. These signals, especially the spindle power, can in fact be easily monitored in real-time fostering a better process and tool wear control through the identification of anomalous machining conditions. Further works will be dedicated to study more in details the wear phenomenon with more tool inspection intervals and supporting the experiments with automated signal process monitoring techniques. The findings of this work support the further developments on the design and the industrial applicability that this innovative tooling technology deserves.
Fig. 10 Average spindle power signal acquired during test $12(\mathrm{Vc}$ $=650 \mathrm{~m} / \mathrm{min}$, downmilling)

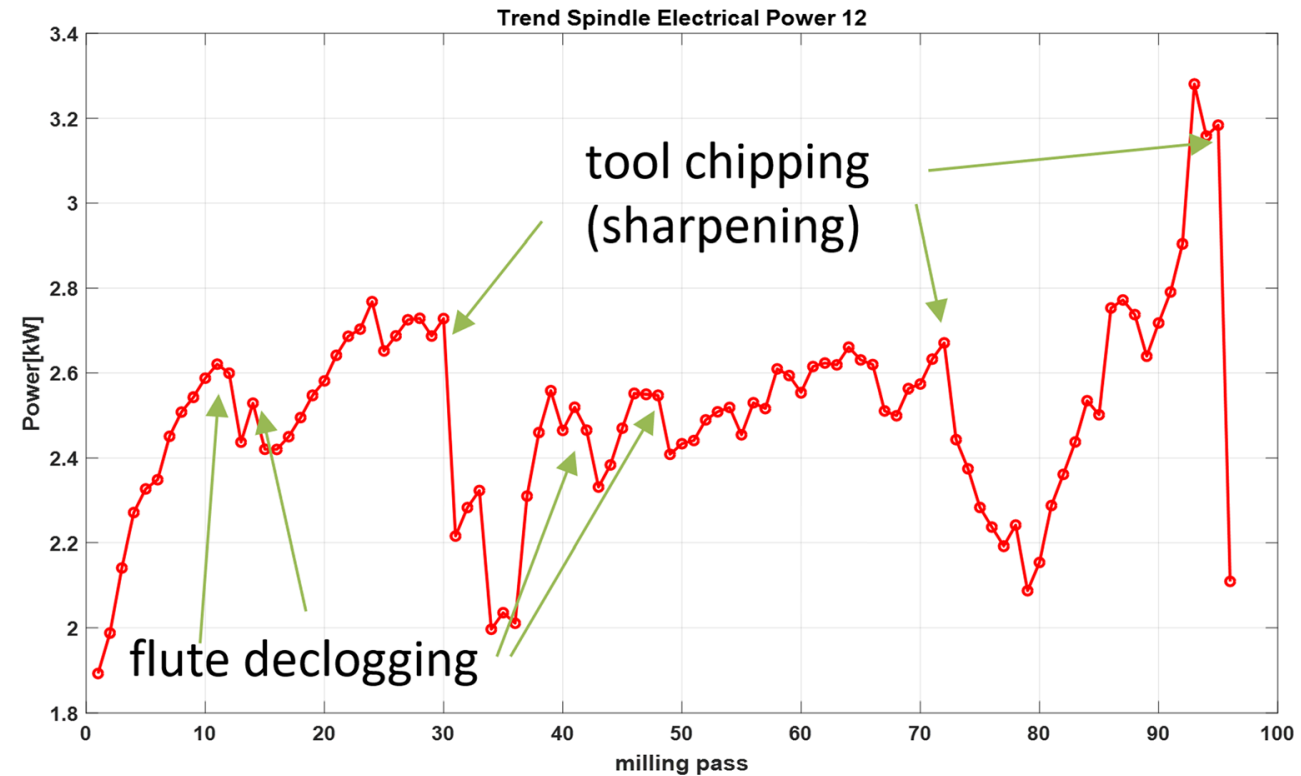



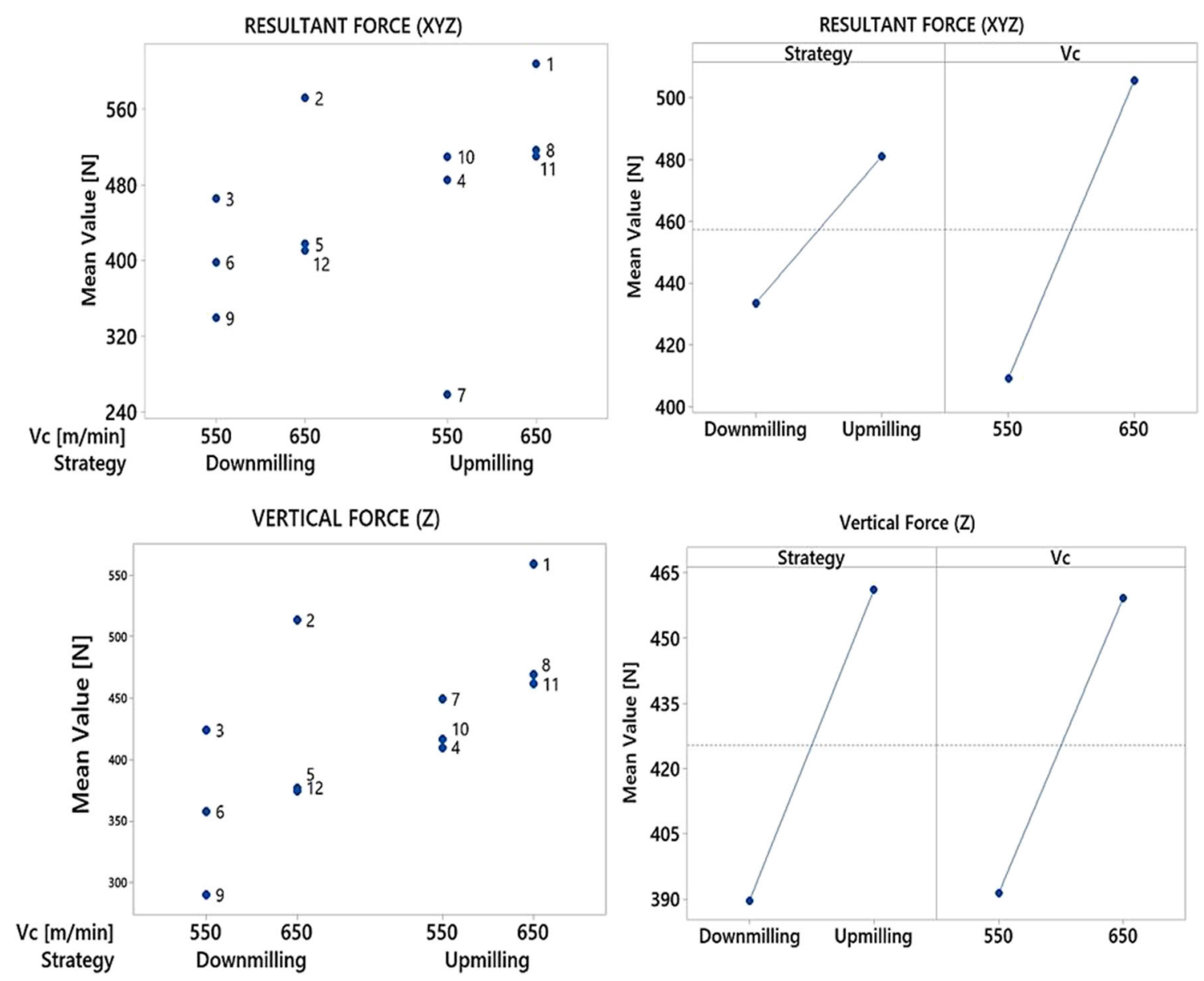

Fig. 11 Individual value plots and main effect plots for the cutting force measurements of all the tests

Fig. 12 Resultant force (XY and $\mathrm{Z}$ ) at the workpiece entry during upmilling (test 1) and downmilling (test 5 ). $\mathrm{Vc}=650$ $\mathrm{m} / \mathrm{min}$. Cutting pass 25

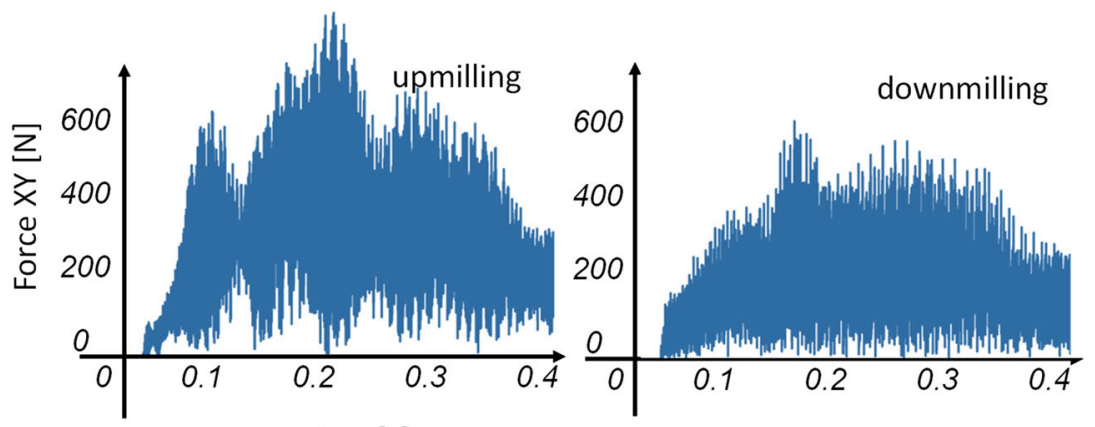

Time [s]

Time $[s]$

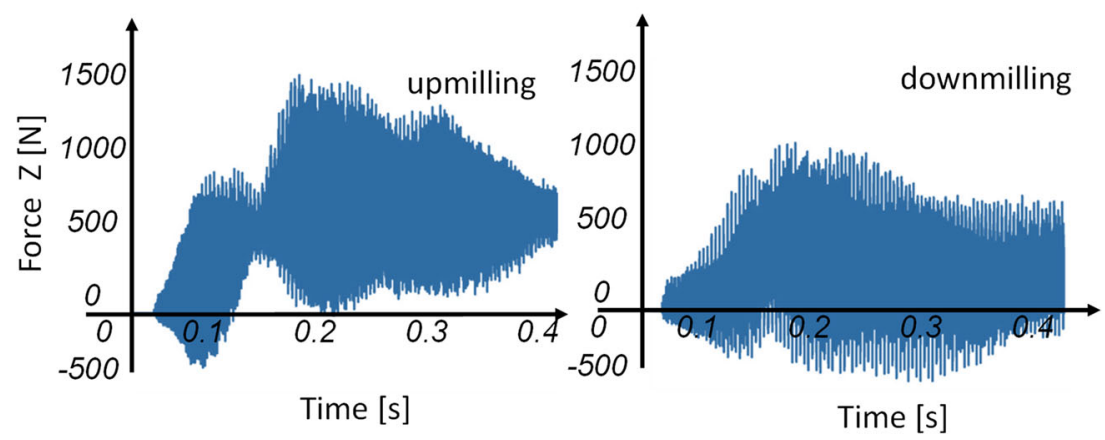


Force $X$ Force $Y$ Force $Z$

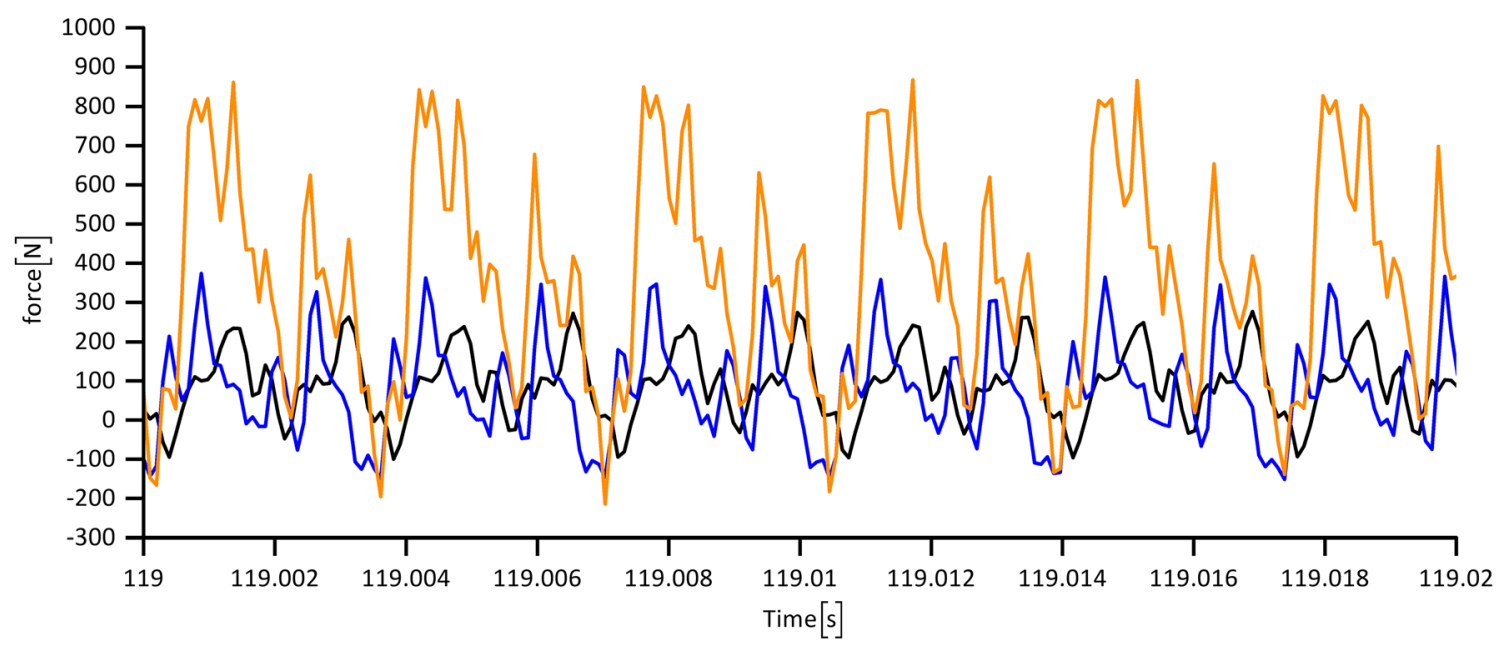

FFT Force Amplitude FFT Force Y Amplitude FFT Force Z Amplitude

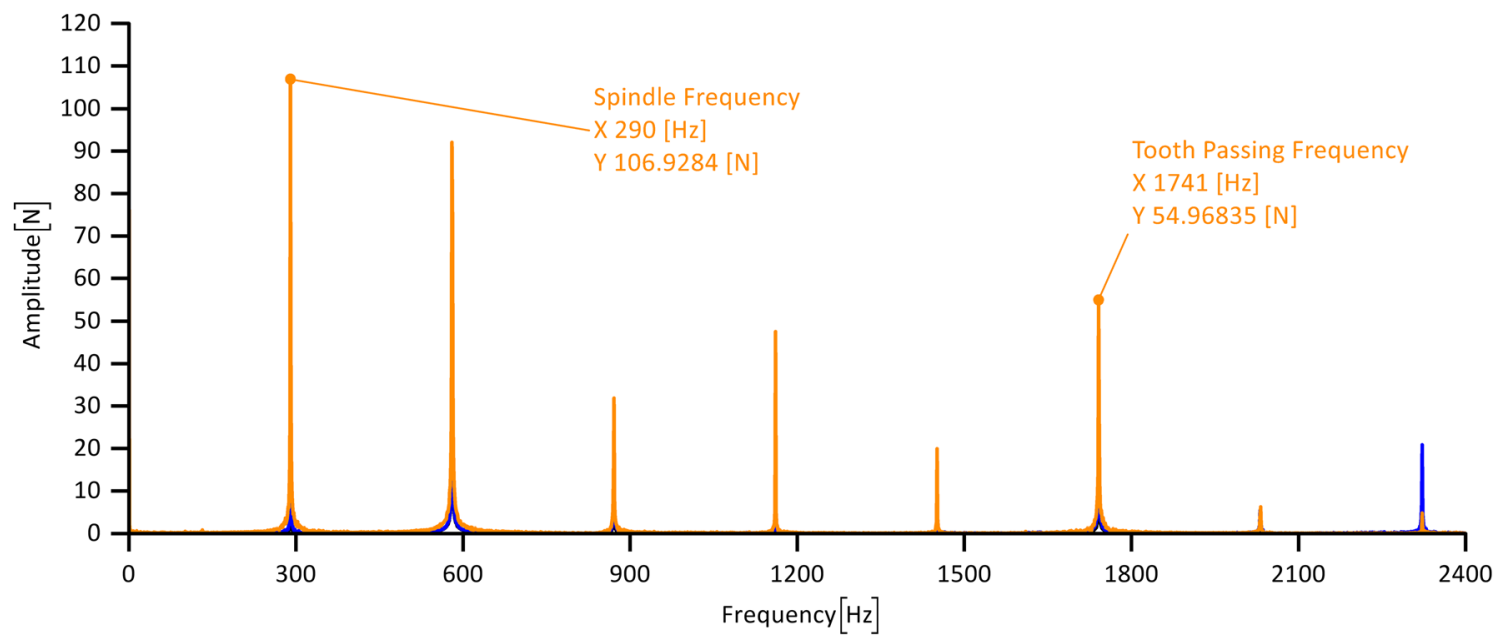

Fig. 13 Cutting forces in downmilling with $\mathrm{Vc}=650 \mathrm{~m} / \mathrm{min}$ (test 5 - pass 10). Forces in $\mathrm{X}, \mathrm{Y}$, and $\mathrm{Z}$ directions in time, 5 complete revolutions, and 1 partial (above). Forces in frequency domain in the same directions (below, frequency resolution $1 \mathrm{~Hz}$ )

Acknowledgements The authors would like to thank Eng. Francesco Cacciatore and Valerio Mussi for supporting the design and the execution of the experimentations.

Author contribution All the authors conceived the experiments. PP, MG, and FP performed the experiments and data analysis. PP and FP wrote the paper. MG, MA, and MM revised the paper.

Funding Open access funding provided by Politecnico di Milano within the CRUI-CARE Agreement.

Data availability The authors confirm that the data and material supporting the findings of this work are available within the article.

\section{Declarations}

Ethical approval Not applicable.
Consent to participate Not applicable.

Consent to publish Not applicable.

Conflict of interest The authors declare no competing interests.

Open Access This article is licensed under a Creative Commons Attribution 4.0 International License, which permits use, sharing, adaptation, distribution and reproduction in any medium or format, as long as you give appropriate credit to the original author(s) and the source, provide a link to the Creative Commons licence, and indicate if changes were made. The images or other third party material in this article are included in the article's Creative Commons licence, unless indicated otherwise in a credit line to the material. If material is not included in the article's Creative Commons licence and your intended use is not permitted by statutory regulation or exceeds the permitted use, you will need to obtain permission directly from the copyright holder. To view a copy of this licence, visit http://creativecommons.org/licenses/by/4.0/. 


\section{References}

1. Kaya E, Akyuz B (2017) Effects of cutting parameters on machinability characteristics of Ni-based superalloys: a review. De Gruyter OPEN Open Engineering 7(1). https://doi.org/10.1515/eng-20170037

2. Kruk A, Wusatowska-Sarnek AM, Ziętara M, Jemielniak K, Siemiątkowski Z, Czyrska-Filemonowicz A (2018) Characterization on white etching layer formed during ceramic milling of Inconel 718. Met Mater Int 24:1036-1045

3. Tian X, Zhao J, Zhao J, Gong Z, Dong Y (2013) Effect of cutting speed on cutting forces and wear mechanisms in high-speed face milling of Inconel 718 with Sialon ceramic tools. Int JAdv Manuf Tech 69:2669-2678

4. Celik A, Sert Alağaç M, Turan S, Kara A, Kara F (2017) Wear behavior of solid SiAlON milling tools during high speed milling of Inconel 718. Wear 378-379:58-67. https://doi.org/10.1016/j. wear.2017.02.025

5. M'Saoubi R et al (2015) High performance cutting of advanced aerospace alloys and composites materials. CIRP Annals Manufacuring tech 64:557-580

6. Finkeldei D, Sexauer M, Bleicher F (2019) End milling of Inconel 718 using solid Si3N4 ceramic cutting tools. Procedia CIRP 81: $1131-1135$

7. Ulutan D, Pleta A, Henderson A, Mears L (2015) Comparison and cost optimization of solid tool life in end milling nickel-based superalloy. Procedia Manufacturing 1:522-533. https://doi.org/10. 1016/j.promfg.2015.09.024

8. Grguraš D, Kern M, Pušavec F (2019) Cutting performance of solid ceramic and carbide end milling tools in machining of nickel based alloy Inconel 718 and stainless steel 316L. Advances in Production Engineering \& Management 14(1):27-38
9. Zheng G, Zhao J, Gao Z, Cao Q (2012) Cutting performance and wear mechanisms of Sialon-Si3N4 graded nano-composite ceramic cutting tools. Int J Adv Manuf Technol 58(1-4):19-28. https://doi. org/10.1007/s00170-011-3379-2

10. Yin $Q$ et al (2020) Recent progress of machinability and surface integrity for mechanical machining Inconel 718: a review. Int J Adv Manuf Technol 109:215-245

11. Fang N, Pai P, Edwards N (2013) A comparative study of highspeed machining of Ti-6Al-4V and Inconel 718 - part I: effect of dynamic tool edge wear on cutting forces. Int J Adv Manuf Technol 68(5-8):1839-1849. https://doi.org/10.1007/s00170-013-4981-2

12. Fang N, Pai P, Edwards N (2013) A comparative study of highspeed machining of Ti-6Al-4V and Inconel 718 - part II: effect of dynamic tool edge wear on cutting vibrations. Int J Adv Manuf Technol 68(5-8):1417-1428. https://doi.org/10.1007/s00170-0134931-z

13. Akhtar W, Sun J, Chen W (2016) Effect of machining parameters on surface integrity in high speed milling of super alloy GH4169/ Inconel 718. Mater Manuf Process 31(5):620-627. https://doi.org/ $10.1080 / 10426914.2014 .994769$

14. Ning F, Wang F, Jia Z, Ma J (2014) Chip morphology and surface roughness in high-speed milling of nickel-based superalloy Inconel 718. Int J Mach Mach Mater 15(3-4):285-299. https://doi.org/10. 1504/IJMMM.2014.060554

15. Huaizhong L, Hao Z, Xiaoqi C (2002) Study of cutting force variation in on-line tool condition monitoring of end milling Inconel 718 with coated carbide inserts. SIMTech Technical Report 1-22: 296-304. https://doi.org/10.1016/j.jmatprotec.2006.07.009

Publisher's note Springer Nature remains neutral with regard to jurisdictional claims in published maps and institutional affiliations. 